\title{
Transtracheal Lidocaine as an Adjunct to Intraoperative Propofol During Parotidectomy
}

\author{
Prasanth Mohan ${ }^{1}$, Aneesh Lakshmanan ${ }^{2}$, Moni Ann Thomas ${ }^{3}$ \\ ${ }^{1}$ Assistant Professor, Department of Anaesthesia, Sree Narayana Institute of Medical Sciences, Chalakka, Ernakulam, ${ }^{2}$ Associate Professor, Department of \\ Anaesthesia, Sree Narayana Institute of Medical Sciences, Chalakka, Ernakulam, ${ }^{3}$ Professor, Department of Anaesthesia, Sree Narayana Institute of \\ Medical Sciences, Chalakka, Ernakulam
}

\section{Abstract}

Background: Minimizing the damage to facial nerve is a matter of utmost priority for a surgeon during parotidectomy. The use of long acting muscle relaxants are avoided as it might hinder identification of the nerve.Transtracheal injection of a local anaesthetic is believed to result in a reduction in requirement of depth of anaesthesia intraoperatively. Objective: To compare the intraoperative propofol consumption, patient's immobility and haemodynamic stability during total parotidectomy under GA, with and without use of a transtracheal block using lidocaine. Subjects and Methods: An observational study was conducted in the Department of Anaesthesia, Amrita institute of Medical sciences and Research centre - Kochi, among 40 patients undergoing parotidectomy under GA, during the period March 2013 to September 2014,with 20 patients receiving an additional transtracheal block using lidocaine and the rest without any additional block. Heart rate, systolic, diastolic and mean arterial blood pressures were documented at various time intervals. Intraoperatively total propofol consumption (bolus and infusion) and number of patient movements, if any, were documented. The data thus collected was properly coded and entered in Microsoft Excel and analysis was done using the software SPSS version 16.0. Results: Intra operative propofol consumption and patient movements were significantly lower in group which received trans tracheal block.Mean heart rate, systolic blood pressure, diastolic blood pressure as well as mean arterial pressure at various time intervals were comparable between the two groups. Conclusion: Trans tracheal block can be practiced as a safe alternative to propofol infusion during surgeries where muscle relaxants are to be avoided.

Keywords: Parotidectomy, trans tracheal block, lidocaine.

Corresponding Author: Dr. Aneesh Lakshmanan, Associate Professor, Department of Anaesthesia, Sree Narayana Institute of Medical Sciences, Chalakka, Ernakulam.

Received: March 2019

Accepted: March 2019

\section{Introduction}

The parotid glands are the largest salivary glands in humans and are frequently involved in disease processes. Approximately $25 \%$ of parotid masses are non-neoplastic; the remaining $75 \%$ are neoplastic. Parotidectomy with preservation of facial nerve function is the standard treatment for tumors of the parotid gland. As the gland is divided into a superficial and deep portion by the facial nerve, which passes through the gland, surgery to treat parotid gland tumors has to be very precise. The surgical goal is to remove the entire tumor without harming the facial nerve. Despite efforts by surgeons, postoperative facial nerve paresis and paralysis are the most frequent early complication of parotid gland surgery. ${ }^{[1,2]}$ Though many surgical approaches had been described to minimize facial nerve damage intraoperatively, identification of the nerve using a nerve locator yields satisfactory results. ${ }^{[3]}$ So general anaesthesia, with the routine use of non-depolarizing muscle relaxants becomes impractical in these cases. As muscle relaxants interfere with conduction at neuromuscular junction, a muscle twitch may fail to manifest even if the nerve had been stimulated by the electrical stimulus. So during these surgeries the uses of long acting muscle relaxants are avoided.

Usually to ensure intraoperative patient immobility propofol infusion is administered. By analyzing the minimum alveolar concentration of various inhalational anaesthetics, it can be inferred that intubation generates stronger noxious stimuli than surgical stimuli, as minimum alveolar concentration for intubation is more than minimum alveolar concentration for incision for all volatile anaesthetic agents.

Transtracheal injection of a local anaesthetic agent, by abolishing the laryngeal and tracheal stimulation by the endotracheal tube, is believed to result in a reduction in requirement of depth of anaesthesia intraoperatively. ${ }^{[5-10]}$ Hence this study was conducted with the objective of comparing the intraoperative propofol consumption, patient's immobility and haemodynamic stability during total parotidectomy under general anaesthesia, with and without use of a transtracheal block using lidocaine. 


\section{Subjects and Methods}

After getting approval from the Institutional ethical committee, an observational study was conducted in the Department of Anaesthesia, Amrita institute of Medical sciences and Research centre - Kochi, among patients undergoing parotidectomy, during the period March 2013 to September 2014.

A pilot study was initially conducted among 20 patients who underwent parotidectomy, of which 10 patients (Group A) received a transtracheal injection of 4 milliliter of $4 \%$ lidocaine just before induction of GA, and the remaining 10 patients (Group B) did not receive the transtracheal block. In group A only $20 \%$ showed intra operative movements whereas in group B 70\% showed intra operative movements Using this data minimum sample required for the current study was calculated using the formula $n=2 \underline{(Z \alpha+Z \beta) 2 P Q}=15$ in each group

$(\mathrm{P} 1-\mathrm{P} 2) 2$

Hence this study was conducted among 40 patients of American Society of Anaesthesiologists physical status (ASA) I and II, who underwent total parotidectomy under general anaesthesia with endotracheal intubation.

All patients underwent a detailed pre-anaesthesia evaluation and on the night prior to surgery all were pre-medicated with oral ranitidine 150 milligram and metoclopromide 10 milligram which were repeated on the day of surgery with sips of water. Patients were kept nil orally 8 hours prior to surgery.

After shifting the patient to operation theatre an $18 \mathrm{G}$ peripheral line was put under local anaesthesia. Pulse oximeter, electrocardiogram and non-invasive blood pressure monitors were connected. General anaesthesia (GA) was induced and maintained in all patients following a standardized protocol. All patients received glycopyrrolate 0.2 milligram, midazolam 2 milligram and morphine 0.2 milligram per kilogram body weight intravenously.

As in the piolet study, Group A patients received a transtracheal injection of 4 milliliter of $4 \%$ lidocaine just before induction of GA, whereas Group B patients did not receive the transtracheal block. All patients were induced with propofol 2.5 milligram per kilogram body weight followed by suxamethonium 2 milligram per kilogram body weight intravenously to facilitate laryngoscopy and intubation. Endotracheal intubation was performed with 7-8 $\mathrm{mm}$ cuffed endotracheal tube. A bite block was kept to prevent biting of endotracheal tube in case the patient became light intraoperatively. Anaesthesia was maintained with oxygen $(33 \%)$, nitrous oxide $(66 \%)$ and isoflurane (1$1.5 \%$ ) with mechanical ventilation to maintain end tidal carbon dioxide levels between $30-35 \mathrm{~mm}$ of $\mathrm{Hg}$.

In group $\mathrm{A}$, if the patient moved, bucked on endotracheal tube or if there were signs of inadequate depth of anaesthesia like tachycardia (heart rate $>100$ /minute) or hypertension (systolic BP $>140 \mathrm{~mm}$ of $\mathrm{Hg}$ ), plane of anaesthesia was deepened with a bolus of propofol 30 milligram intravenously and an infusion of propofol was started at a rate of 2 milligram per kilogram per hour. In group B an intravenous infusion of propofol was started at a rate of 2 milligram per kilogram per hour after intubation and if there were signs of inadequate depth of anaesthesia a bolus of propofol 30 milligram intravenously was given. Propofol bolus of 30 milligram was repeated in both groups, if required in addition to infusion.

Heart rate, systolic, diastolic and mean arterial blood pressures were documented at preinduction, 5, 10, 15, 30, 45, 60, 90 and 120 minutes after induction. Intraoperatively total propofol consumption (bolus and infusion) and number of patient movements, if any, were documented and analyzed.

\section{Statistical Analysis:}

The data was properly coded and entered in Microsoft Excel. Further analysis was done using the software SPSS version 20.0. Qualitative variables were expressed as percentages and quantitative as mean with standard deviation. To compare the means of continuous parameters between groups Student's independent samples t-test was used. For finding the association with categorical variables Pearson Chi-square test with Yates' continuity correction was performed. Statistical significance was set at a p value $<0.05$.

\section{Results}

The mean age in group A was $49.5 \pm 13.57$ years, where as it was $48.9 \pm 11.63$ years in group $\mathrm{B}$. The age comparison showed no significant difference in its distribution among the two groups $(\mathrm{p}=0.88)$. The two groups were comparable with respect to weight $(\mathrm{p}=0.147)$ as well as height $(\mathrm{p}=0.719)$ [Table 1]. The group comparison revealed no significant difference in its distribution among the two groups with regard to distribution of gender. Both groups had $75 \%$ males and $25 \%$ females. The ASA distribution demonstrated no significant difference among the two groups with regard to ASA physical status. Both groups had $55 \%$ of patients belonging to ASA I and $45 \%$ belonging to ASA II.

When the intra-operative propofol consumption was compared between the two groups, Group A showed very less consumption $(6.0 \pm 15.69)$ when compared to group B $(326.5 \pm 95.05)$. This difference was found to be statistically significant on students t test $(\mathrm{p}<0.001)$. Likewise when the patient movements were compared between two groups, patient movements were more in group B (80\%) when compared with group A (15\%) and the difference was found to be statistically significant on Chi square test $(\mathrm{p}<0.001)$.

Comparison of baseline mean heart rate, systolic blood pressure, diastolic blood pressure and mean arterial pressure showed that there was no significant difference among the two groups [Table 2]. When the difference of mean heart rate, systolic blood pressure, diastolic blood pressure as well as mean arterial pressure at various time intervals from baseline were compared between groups, it was found that there was no significant difference between groups at 5,10 , $15,30,45,60,90$ and 120 minutes $(\mathrm{p}>0.05)$ [Table 3, Figure $1 \& 2]$.

Table 1: Comparison of mean weight and height of study subjects of two groups.

\begin{tabular}{|l|l|l|l|l|}
\hline Parameter & Group & Mean & SD & P value \\
\hline \multirow{2}{*}{ Weight (Kg) } & Group A & 65.10 & 10.4 & \multirow{3}{*}{0.147} \\
\cline { 2 - 4 } & Group B & 70.10 & 10.94 & \multirow{2}{*}{0.719} \\
\hline \multirow{2}{*}{ Height (CM) } & Group A & 164.55 & 8.76 & \\
\cline { 2 - 4 } & Group B & 165.55 & 8.72 & \multicolumn{2}{|c}{} \\
\hline
\end{tabular}


Table 2: Comparison of baseline parameters of study subjects of two groups.

\begin{tabular}{|l|l|l|l|l|}
\hline Parameter & Group & Mean & SD & P value \\
\hline Heart rate & Group A & 86.65 & 15.29 & 0.64 \\
\cline { 2 - 4 } & Group B & 84.7 & 10.37 & \\
\hline \multirow{2}{*}{$\begin{array}{l}\text { Systolic blood } \\
\text { pressure }\end{array}$} & Group A & 135.95 & 15.58 & \multirow{2}{*}{0.98} \\
\cline { 2 - 4 } $\begin{array}{l}\text { Diastolic blood } \\
\text { pressure }\end{array}$ & Group B & 136.1 & 17.89 & \\
\cline { 2 - 4 } & Group B & 85.4 & 10.73 & 0.38 \\
\hline $\begin{array}{l}\text { Mean arterial } \\
\text { pressure }\end{array}$ & Group A & 101.25 & 10.04 & \\
\cline { 2 - 4 } & Group B & 107.35 & 14.74 & \\
\hline
\end{tabular}

Table 3: Comparison of Heart rate and mean arterial pressure of study subjects of two groups over 2 hours.

\begin{tabular}{|c|c|c|c|c|c|c|c|}
\hline \multirow[t]{2}{*}{ Time } & \multirow[t]{2}{*}{ Group } & \multicolumn{2}{|c|}{ Heart Rate } & \multirow[t]{2}{*}{$\begin{array}{l}P \\
\text { value }\end{array}$} & \multicolumn{2}{|c|}{$\begin{array}{l}\text { Mean Aterial } \\
\text { Pressure }\end{array}$} & \multirow[t]{2}{*}{$\begin{array}{l}P \\
\text { value }\end{array}$} \\
\hline & & Mean & SD & & Mean & SD & \\
\hline \multirow[t]{2}{*}{$5 \min$} & A & -0.15 & 9.32 & \multirow[t]{2}{*}{0.16} & 23.70 & 13.70 & \multirow[t]{2}{*}{0.06} \\
\hline & B & 6.10 & 5.97 & & 14.20 & 171.17 & \\
\hline \multirow[t]{2}{*}{$10 \mathrm{~min}$} & A & 2.45 & 12.06 & \multirow[t]{2}{*}{0.46} & 28.55 & 15.06 & \multirow[t]{2}{*}{0.31} \\
\hline & B & -0.65 & 14.36 & & 22.60 & 21.14 & \\
\hline \multirow[t]{2}{*}{$15 \mathrm{~min}$} & A & 4.05 & 14.81 & \multirow[t]{2}{*}{0.94} & 22.65 & 12.11 & \multirow[t]{2}{*}{0.24} \\
\hline & B & 3.75 & 12.07 & & 28.35 & 17.36 & \\
\hline \multirow[t]{2}{*}{ 30min } & A & 7.10 & 15.08 & \multirow[t]{2}{*}{0.57} & 24.30 & 12.06 & \multirow[t]{2}{*}{0.13} \\
\hline & B & 9.55 & 11.82 & & 32.35 & 18.89 & \\
\hline \multirow[t]{2}{*}{$45 \mathrm{~min}$} & $\mathrm{~A}$ & 12.45 & 12.47 & \multirow[t]{2}{*}{0.92} & 22.80 & 14.24 & \multirow[t]{2}{*}{0.32} \\
\hline & $\mathrm{B}$ & 12.10 & 9.06 & & 27.75 & 16.91 & \\
\hline \multirow[t]{2}{*}{$60 \mathrm{~min}$} & A & 11.40 & 11.19 & \multirow[t]{2}{*}{0.82} & 19.85 & 14.10 & \multirow[t]{2}{*}{0.24} \\
\hline & $\mathrm{B}$ & 12.15 & 8.83 & & 26.25 & 19.32 & \\
\hline \multirow[t]{2}{*}{$90 \mathrm{~min}$} & $\mathrm{~A}$ & 12.60 & 13.34 & \multirow[t]{2}{*}{0.63} & 20.50 & 14.36 & \multirow[t]{2}{*}{0.71} \\
\hline & B & 10.90 & 8.52 & & 22.25 & 15.99 & \\
\hline \multirow[t]{2}{*}{$120 \mathrm{~min}$} & A & 12.15 & 15.69 & \multirow[t]{2}{*}{0.84} & 12.55 & 16.34 & \multirow[t]{2}{*}{0.14} \\
\hline & B & 11.30 & 10.50 & & 20.15 & 15.12 & \\
\hline
\end{tabular}

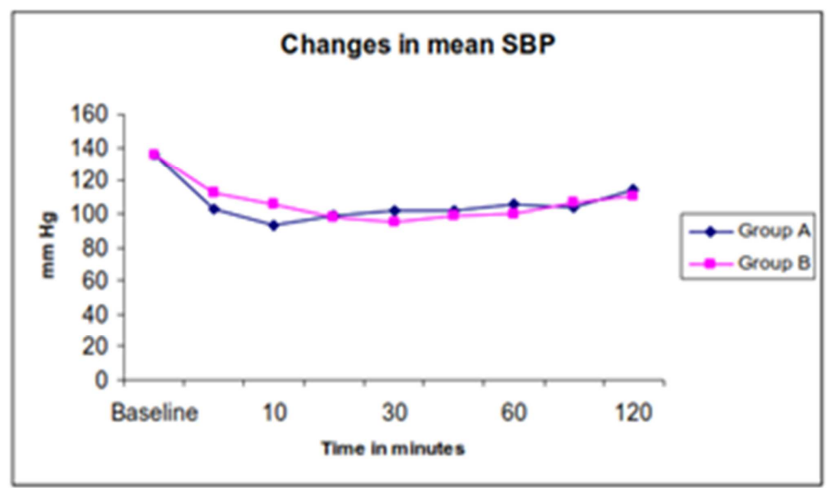

Figure 1: Line diagram comparing changes in systolic blood pressure of study subjects of two groups over 2 hours.

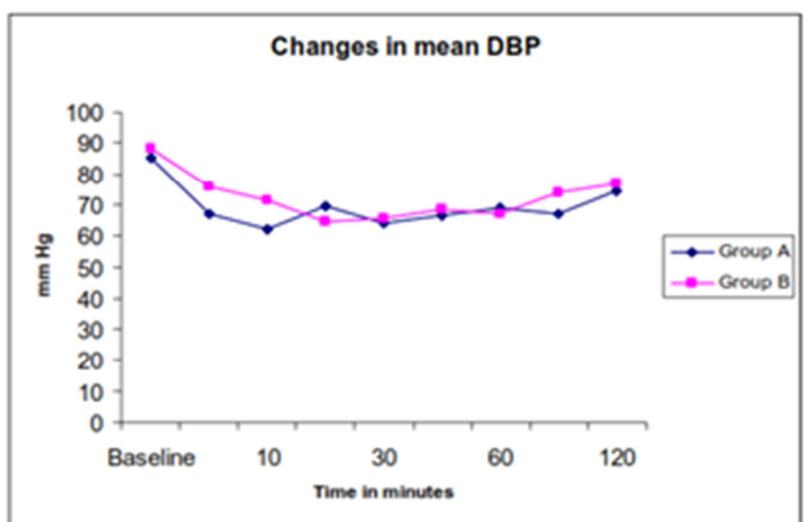

Figure 2: Line diagram comparing changes in diastolic blood pressure of study subjects of two groups over 2 hours.

\section{Discussion}

In the present study transtracheal injection of lidocaine was found to be an effective alternative to propofol infusion, when long acting muscle relaxants needed to be avoided. This was in agreement with a previous study by Rajan et al. ${ }^{[4]}$ The major difference was that in that study the surgical population included post brachial plexus injury patients undergoing nerve anastomosis. Whereas our study was conducted in patients undergoing parotidectomy. In the previous study it was found that intraoperative propofol requirement in the presence of transtracheal block was significantly less (6 vs $377 \mathrm{mg}$ ). In our study it was found that propofol requirement in the presence and absence of transtracheal block was $6 \pm 15.69 \mathrm{mg}$ and $326.5 \pm 95.05 \mathrm{mg}$ respectively. Though the surgical population was different, the observation made in our study was in agreement with the previous one.

The major differences from the previous study was that propofol bolus in our study was body weight based, whereas it was not so in the study by Rajan et al. Compared to the previous study the number of intraoperative patient movements in our study was less. This could be because there was no baseline propofol infusion in their study. Propofol infusion was started only following three or more patient movements in 30 minutes. But in our study the control group received propofol infusion from the beginning of surgery itself without waiting for patient movements to manifest. This could have resulted in less patient movements in comparison with the previous study. On the other hand mean heart rate, systolic blood pressure, diastolic blood pressure as well as mean arterial pressure at various time intervals were comparable between the two groups.

\section{Conclusion}

In the present study it was observed that transtracheal block resulted in significantly less number of intraoperative patient movements ( 3 vs. 18) and propofol requirement (6 15.69 vs $326.5 \pm 95.05 \mathrm{mg}$ ) in comparison with the group which did not receive the block. Hemodynamically both groups were stable intraoperatively. Hence it is concluded that trans tracheal block can be practiced as a safe and successful alternative to propofol infusion during surgeries where muscle relaxants are to be avoided.

\section{Acknowledgments:}

The authors acknowledge the support received from the staff - Department of Anaesthesia, Amrita institute of Medical sciences and Research centre - Kochi in the completion of the study.

\section{References}

1. Marchese-Ragona R, De Filippis C, Marioni G, Staffieri A. Treatment of complications of parotid gland surgery. ActaOtorhinolaryngol Ital. 2005; 25(3): 174-8

2. Lowry TR, Gal TJ, Brennan JA. Patterns of use of facial nerve monitoring during parotid gland surgery. Otolaryngol Head Neck Surg. 2005; 133(3): 313-8.

3. Terrell JE, Kileny PR, Yian C, Esclamado RM, Bradford CR, Pillsbury 
MS, et al. Clinical outcome of continuous facial nerve monitoring during primary parotidectomy. Arch Otolaryngol Head Neck Surg. 1997; 123: 1081-7.

4. Rajan S, Puthenveetil N, Thankappan K, Paul J. Transtracheal lidocaine injection reduces the anesthetic requirements in brachial plexus surgeries. Anesth Essays Res. 2013; 7(1): 110-115.

5. Sands RP, Yarussi AT. Regional anesthesia for bronchoscopy. Tech Reg Anesth Pain Manage. 1998; 2: 30-4.

6. Fernandez A, Tedde ML, Filomeno LT, Suso FV. Anesthesia for bronchoscopy. Rev HospClinFac Med Sao Paulo. 1992; 47:125-7.

7. Scharf ML, Panichello C, Murphy DM. Routine use of transtracheal anaesthetic block during flexible fiberoptic bronchoscopy: An evaluation of safety and effect on moderate sedation. Chest. 2006;130:4.

8. Ehrenwerth J, Brull SJ. Anesthesia for thoracic diagnosticprocedures. In: Kaplan JA, Slinger PD (eds). Thoracic anesthesia. 3rd edition. Philadelphia: Churchill Livingstone; 2003: p174-95.

9. Wilson RS. Anesthesia for bronchoscopy and mediastinoscopy. In: Youngberg JA, Lake CL, Wilson RS (eds). Cardiac, vascular and thoracic anesthesia. New York: Churchill Livingstone; 2000:p660-9.

10. Takita K, Morimoto Y, Kemmotsu O. Tracheal lidocaine attenuates the cardiovascular response to endotracheal intubation. Can J Anaesth. 2001; 48: 732-6.

Copyright: (c) the author(s), publisher. Academia Anesthesiologica International is an Official Publication of "Society for Health Care \& Research Development". It is an open-access article distributed under the terms of the Creative Commons Attribution Non-Commercial License, which permits unrestricted non-commercial use, distribution, and reproduction in any medium, provided the original work is properly cited.

How to cite this article: Mohan P, Lakshmanan A, Thomas MA. Transtracheal Lidocaine as an Adjunct to Intraoperative Propofol During Parotidectomy. Acad. Anesthesiol. Int. 2019;4(1):49-52.

DOI: dx.doi.org/10.21276/aan.2019.4.1.11

Source of Support: Nil, Conflict of Interest: None declared. 